\begin{tabular}{|c|l|}
\hline Title & Evolution of the north-polar cap of Mars: a modelling study \\
\hline Author(s) & Greve, Ralf; Mahaj an, Rupali A.; Segschneider, Joachim; Grieger, Björn \\
\hline Citation & $\begin{array}{l}\text { Planetary and Space Science, 52(9), 775-787 } \\
\text { https://doi.org/10.1016/.pss.2004.03.007 }\end{array}$ \\
\hline Issue Date & 2004_08 \\
\hline Doc URL & http://hdl.handle.net/2115/32734 \\
\hline Type & article(author version) \\
\hline File Information & Greve_etal_2004_PSS.pdf \\
\hline
\end{tabular}

Instructions for use 


\title{
Evolution of the north-polar cap of Mars: a modelling study
}

\author{
Ralf Greve (1,2), Rupali A. Mahajan (3), \\ Johchim Segschneider (3) and BJörn Grieger (3)
}

(1) Institute of Low Temperature Science, Hokkaido University, Kita-19, Nishi-8, Kita-ku, Sapporo 060-0819, Japan

(2) Department of Mechanics, Darmstadt University of Technology, Hochschulstraße 1, D-64289 Darmstadt, Germany

(3) Max Planck Institute for Aeronomy, Max-Planck-Straße 2, D-37191 Katlenburg-Lindau, Germany

March 29, 2004

Correspondence to: R. Greve (greve@lowtem.hokudai.ac.jp) 


\begin{abstract}
Celestial-mechanical computations show that, even stronger than for Earth, Mars is subject to Milanković cycles, that is, quasi-periodic variations of the orbital parameters obliquity, eccentricity and precession. Consequently, solar insolation varies on time-scales of $10^{4}-10^{5}$ years. It has long been supposed that this entails climatic cycles like the terrestrial glacialinterglacial cycles. This hypothesis is supported by the light-dark layered deposits of the north- and south-polar caps indicating a strongly varying dust content of the ice due to varying climate conditions in the past. This study aims at simulating the dynamic and thermodynamic evolution of the north-polar cap (NPC) of Mars with the ice-sheet model SICOPOLIS. The boundary conditions of surface accumulation, ablation and temperature are derived directly from the solar-insolation history by applying the newly developed Mars Atmosphere-Ice Coupler MAIC. We consider steady-state scenarios under present climate conditions as well as transient scenarios over climatic cycles. It is found that the NPC is most likely not in steady state with the present climate. The topography of the NPC is mainly controlled by the history of the surface mass balance. Ice flow, which is of the order of $1 \mathrm{~mm} \mathrm{a}^{-1}$, plays only a minor role. In order to build up the present cap during the last five million years of relatively low obliquities, a present accumulation rate of $\geq 0.25 \mathrm{~mm}$ water equiv. $\mathrm{a}^{-1}$ is required. Computed basal temperatures are far below pressure melting for all simulations and all times.
\end{abstract}

\title{
1 Introduction
}

The Martian poles are both covered by ice caps. The seasonal caps, which can extend down to latitudes of approximately $55^{\circ} \mathrm{N} / \mathrm{S}$, consist of only some ten centimeters of $\mathrm{CO}_{2}$ snow which sublimes into the atmosphere during the respective spring season. The smaller residual caps poleward of approximately $80^{\circ} \mathrm{N} / \mathrm{S}$ are underlain by massive topographic structures known as the polar layered deposits (Thomas et al. 1992). The complexes composed of the residual caps and the layered deposits are referred to as the north- and south-polar cap (NPC/SPC), respectively (e.g., Johnson et al. 2000, Byrne and Murray 2002, Greve et al. 2003). Owing to the Mars Orbiter Laser Altimeter (MOLA) measurements of the Mars Global Surveyor (MGS) spacecraft, the surface topographies of the NPC and SPC have been mapped very precisely (Zuber et al. 1998, Smith et al. 1999). The NPC topography, which is our focus, is shown in Fig. 1 (left panel).

This study is a continuation of previous ones by Greve (2000b) and Greve et al. (2003) in which the NPC was treated in a simplified fashion as a paraboloid cap. The topography evolution was prescribed because of limited knowledge about climatic forcing. Here, we 

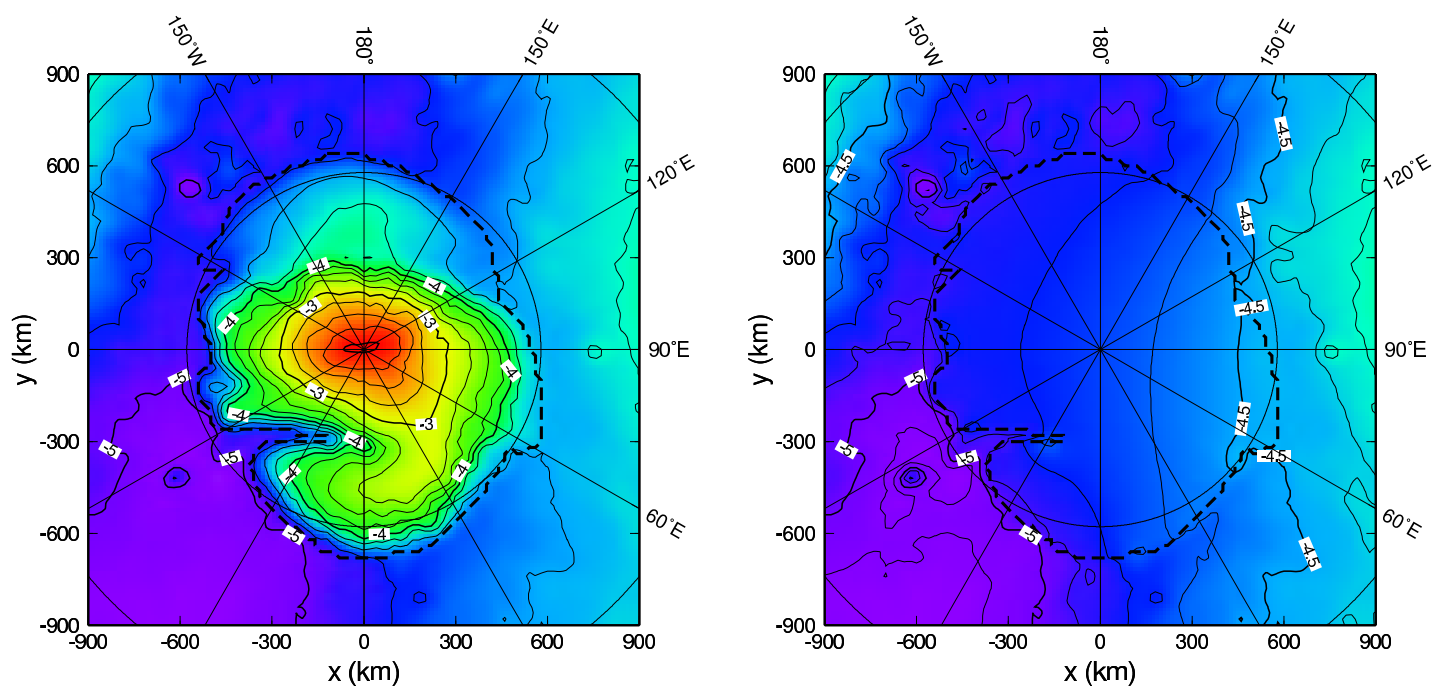

Figure 1: Left: MOLA surface topography of the north-polar cap, $z=h(x, y, t=0)$ (in $\mathrm{km}$ relative to the reference geoid; Zuber et al. 1998, Smith et al. 1999). Right: Computed topography of the equilibrated ground for ice-free conditions, $z=b_{0}(x, y)$ (in km relative to the reference geoid). The heavy-dashed line in each panel indicates the ice margin.

aim at overcoming this simplification by constructing a simple model called MAIC (Mars Atmosphere-Ice Coupler). MAIC parameterizes the surface temperature, ice accumulation and ablation mainly as a function of the Milanković parameter obliquity (e.g., Laskar et al. 2002). Dynamic/thermodynamic simulations are carried out for the NPC with the ice-sheet model SICOPOLIS (SImulation COde for POLythermal Ice Sheets). Two different types of simulations are considered: (i) steady-state simulations in which the present climate forcing is assumed to be constant over time, and (ii) transient simulations which model explicitly the evolution of the NPC over climatic cycles. Hereby, our central presumption is that the NPC consists mainly of $\mathrm{H}_{2} \mathrm{O}$ ice with physical properties comparable to that of ice in terrestrial ice sheets, so that the NPC is controlled by accumulation, ablation and glacial flow (which are, of course, orders of magnitude smaller than on Earth). Greve et al. (2003) discussed the validity of this presumption in some detail, therefore this is not repeated here.

\section{Ice-sheet model SICOPOLIS}

The dynamic/thermodynamic behaviour of the NPC of Mars is investigated with the ice-sheet model SICOPOLIS. It was originally developed for terrestrial ice sheets and successfully applied to problems of past, present and future glaciation of Greenland, the entire northern hemisphere and Antarctica (cf. Greve 2000a, and references therein). The model describes ice rheologically as an incompressible, heat-conducting, power-law fluid 
with thermo-mechanical coupling due to the strong temperature dependence of the ice viscosity. The strain-rate tensor $\boldsymbol{D}=\operatorname{sym} \operatorname{grad} \boldsymbol{v}(\operatorname{velocity} \boldsymbol{v})$ is given as

$$
\boldsymbol{D}=E A\left(T^{\prime}\right) \sigma^{n-1} \boldsymbol{t}^{\mathrm{D}}
$$

where $\boldsymbol{t}^{\mathrm{D}}$ the Cauchy stress deviator, $\sigma=\left[\operatorname{tr}\left(\boldsymbol{t}^{\mathrm{D}}\right)^{2} / 2\right]^{1 / 2}$ the effective shear stress, $n$ the power-law exponent,

$$
A\left(T^{\prime}\right)=A_{0} e^{-Q / R T^{\prime}}
$$

the flow-rate factor in the form of an Arrhenius law $\left(A_{0}\right.$ : preexponential constant, $Q$ : activation energy, $R$ : universal gas constant, $T^{\prime}$ : temperature relative to the pressure melting point; see Paterson 1994), and $E$ the flow-enhancement factor. The latter is equal to unity for pure ice and can deviate from unity due to the softening or stiffening effect of impurities in the ice. It is distinguished between cold ice with a temperature below the pressure melting point and temperate ice with a temperature at the pressure melting point. The latter is considered as a binary mixture of ice and small amounts of water. The interface that separates cold and temperate ice is monitored using Stefan-type energy flux and mass flux matching conditions.

The model computes the temporal evolution of ice extent, thickness, three-dimensional velocity, temperature, water content and age in response to external forcing. The latter is specified by (i) the mean annual air temperature at the ice surface, (ii) the surface mass balance, that is ice accumulation (snowfall, condensation) minus ablation (melting, sublimation, erosion), (iii) the global sea level (not relevant for Martian applications in the recent past) and (iv) the geothermal heat flux heating the ice mass from below. All computations are carried out in a stereographic plane with standard parallel $71^{\circ} \mathrm{N}$, spanned by the Cartesian coordinates $x$ and $y$. The vertical coordinate $z$ is taken positive upward, and the zero level is the reference geoid. The distortions due to the stereographic projection are corrected by appropriate metric coefficients.

Isostatic depression and rebound of the lithosphere due to changing ice load is described by a local-lithosphere-relaxing-asthenosphere (LLRA) model with an isostatic time lag $\tau_{\text {iso }}$ (Le Meur and Huybrechts 1996, Greve 2001). Owing to the non-local response of the elastic lithosphere plate, local isostatic compensation of the ice load is not likely. We consider this by introducing a fraction of isostatic compensation, $f_{\text {iso }}$, so that the steady-state downward displacement of the lithosphere, $w_{\mathrm{ss}}$, is

$$
w_{\mathrm{ss}}=f_{\text {iso }} \times H \frac{\rho}{\rho_{\mathrm{a}}}
$$

where $H$ is the ice thickness, $\rho$ the ice density and $\rho_{\text {a }}$ the asthenosphere (upper-mantle) 
density (Greve et al. 2003). The actual displacement $w$ as a function of time $t$ is then given by

$$
\frac{\partial w}{\partial t}=-\frac{1}{\tau_{\text {iso }}}\left(w-w_{\mathrm{ss}}\right)
$$

To compute the actual ground (Martian surface without ice) topography $z=b(x, y, t)$, the position of the equilibrated ground for ice-free conditions, $z=b_{0}(x, y)$ is required as a reference:

$$
b(x, y, t)=b_{0}(x, y)-w(x, y, t) .
$$

It is constructed by a smooth extrapolation of the ice-free ground surrounding the NPC,

$$
\begin{aligned}
\nabla^{2} b_{0}(x, y) & =0 & & \text { under the NPC } \\
b_{0}(x, y) & =b(x, y, t=0) & & \text { outside the NPC. }
\end{aligned}
$$

The result is shown in Fig. 1 together with the MOLA surface topography which defines the present ground topography $b(x, y, t=0)$ outside the NPC. In the near future, the MARSIS radar instrument onboard the Mars Express orbiter (see website http://www . marsis. com) may provide direct measurements of the subsurface below the NPC against which this extrapolation can be checked.

The structure of SICOPOLIS is sketched in Fig. 2, and the standard values of the relevant physical parameters used for the simulations herein are listed in Table 1.

\section{Climatic forcing with the coupler MAIC}

For the climatic forcing (surface temperature, accumulation-ablation rate) of the NPC, we will now describe a set of parameterizations driven directly by the orbital parameters obliquity and eccentricity. These have been computed by Laskar et al. (2002) for the last ten million years with a celestial-mechanical model for the whole solar system (obliquity shown in Fig. 3, top panel). The parameterizations are assembled into the module MAIC (Mars Atmosphere-Ice Coupler), used to drive simulations with SICOPOLIS.

\subsection{Surface temperature}

Focus of this study is to obtain basic insight in the evolution and dynamic/thermodynamic properties of the NPC, rather than attempting to simulate the real evolution of the $\mathrm{NPC}$ in detail. It is therefore favourable to replace the complex climatic forcing which the NPC has experienced by simplified, idealized conditions. Further, we do not attempt at disentangling seasonal effects like longer periods of $\mathrm{CO}_{2}$ ice cover during winter at low 


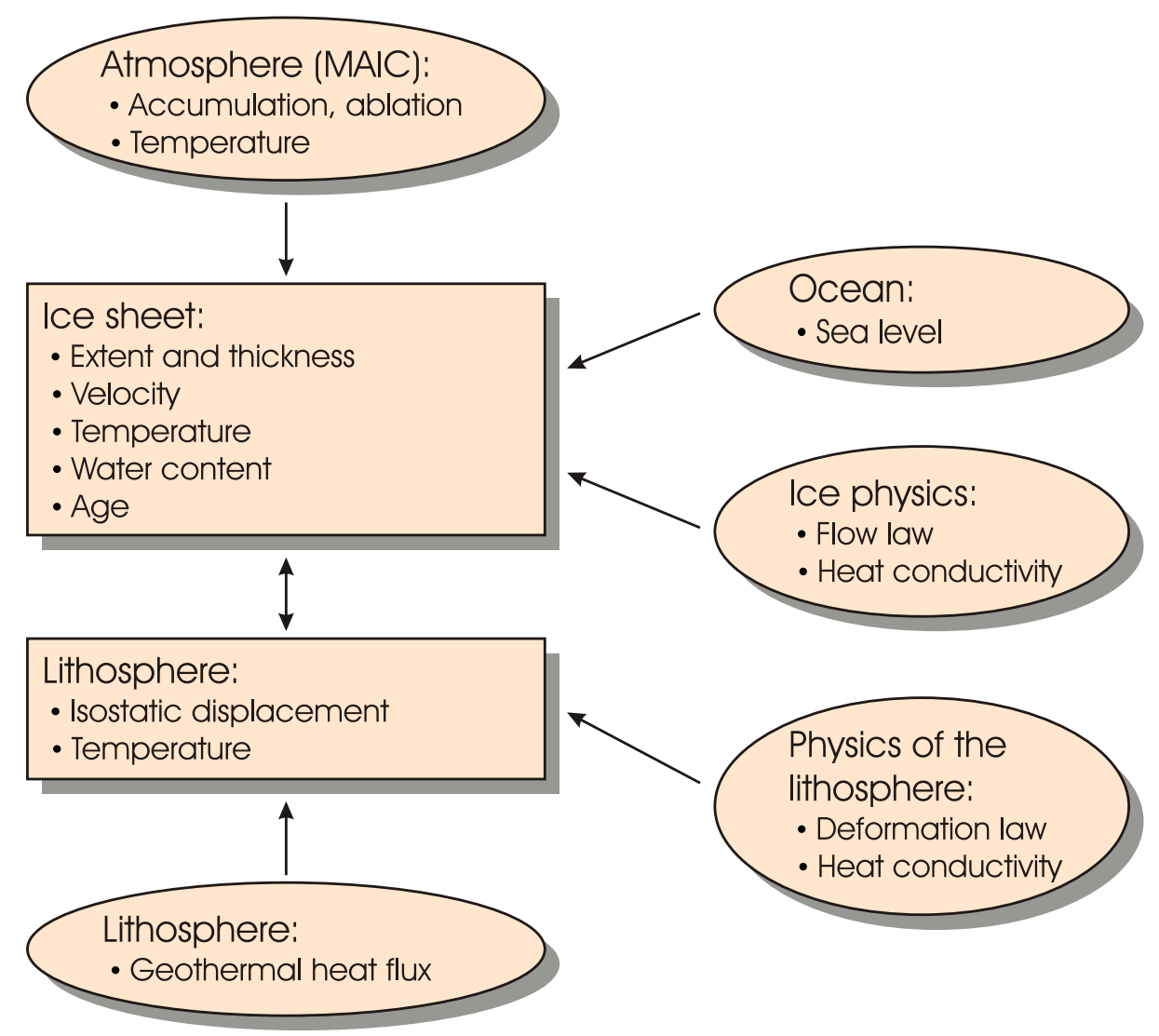

Figure 2: Sketch of the ice-sheet model SICOPOLIS with the coupler MAIC. Rectangular boxes correspond to prognostic model components, oval boxes to inputs from outside the system.

obliquity, or seasonal insolation variations due to eccentricity, and formulate the entire parametrization in mean annual quantities only.

We approximate the obliquity $\theta$ for the last four million years, during which the average was close to the present value $\theta_{0}=25.2^{\circ}$, by a simplified two-cycle obliquity. To this end, we define the main cycle

$$
\theta(t)=\theta_{0}+\hat{\theta}(t) \sin \frac{2 \pi t}{t_{\mathrm{obl}}^{\text {main }}}
$$

with the period $t_{\mathrm{obl}}^{\text {main }}=125 \mathrm{ka}$. The modulation of the amplitude (envelope) is given by

$$
\hat{\theta}(t)=\frac{\hat{\theta}_{\max }+\hat{\theta}_{\min }}{2}-\left(\frac{\hat{\theta}_{\max }-\hat{\theta}_{\min }}{2}\right) \cos \frac{2 \pi t}{t_{\mathrm{obl}}^{\bmod }},
$$

with the maximum amplitude $\hat{\theta}_{\max }=10^{\circ}$, the minimum amplitude $\hat{\theta}_{\min }=2.5^{\circ}$ and the period $t_{\mathrm{obl}}^{\mathrm{mod}}=1.3 \mathrm{Ma}$ (cf. Ward 1992, Touma and Wisdom 1993, Laskar et al. 2002). The resultant obliquity history is shown in Fig. 3 (bottom panel, left ordinate axis).

The mean annual insolation at the north pole of Mars, $I_{\mathrm{np}}^{\text {in }}(t)$, follows from the obliquity 


\begin{tabular}{ll}
\hline Quantity & Value \\
\hline Gravity acceleration, $g$ & $3.72 \mathrm{~m} \mathrm{~s}^{-2}$ \\
Density of ice, $\rho$ & $910 \mathrm{~kg} \mathrm{~m}^{-3}$ \\
Power-law exponent, $n$ & 3 \\
Flow-enhancement factor, $E$ & 3 \\
Preexponential constant, $A_{0}$ & $3.985 \times 10^{-13} \mathrm{~s}^{-1} \mathrm{~Pa}^{-3}$ \\
Activation energy, $Q$ & $60 \mathrm{~kJ} \mathrm{~mol}^{-1}$ \\
Universal gas constant, $R$ & $8.314 \mathrm{~J} \mathrm{~mol}^{-1} \mathrm{~K}^{-1}$ \\
Heat conductivity of ice, $\kappa$ & $9.828 e^{-0.0057 T[\mathrm{~K}]} \mathrm{W} \mathrm{m} \mathrm{m}^{-1} \mathrm{~K}^{-1}$ \\
Specific heat of ice, $c$ & $(146.3+7.253 T[\mathrm{~K}]) \mathrm{J} \mathrm{kg}^{-1} \mathrm{~K}^{-1}$ \\
Latent heat of ice, $L$ & $335 \mathrm{~kJ} \mathrm{~kg}^{-1}$ \\
Clausius-Clapeyron gradient, $\beta$ & $3.3 \times 10^{-4} \mathrm{~K} \mathrm{~m}^{-1}$ \\
Geothermal heat flux, $q_{\mathrm{geo}}$ & $35 \mathrm{~mW} \mathrm{~m}^{-2}$ \\
Fraction of isostatic & \\
compensation, $f_{\text {iso }}$ & 0.65 \\
Isostatic time lag, $\tau_{\text {iso }}$ & $3000 \mathrm{a}$ \\
Asthenosphere density, $\rho_{\mathrm{a}}$ & $3300 \mathrm{~kg} \mathrm{~m}^{-3}$ \\
Density $\times$ specific heat of the & \\
lithosphere, $\rho_{\mathrm{r}} c_{\mathrm{r}}$ & $2000 \mathrm{~kJ} \mathrm{~m}^{-3} \mathrm{~K}^{-1}$ \\
Heat conductivity of the & \\
lithosphere, $\kappa_{\mathrm{r}}$ & $3 \mathrm{~W} \mathrm{~m}-1 \mathrm{~K}^{-1}$ \\
\hline
\end{tabular}

Table 1: Standard physical parameters of the ice-sheet model.

$\theta$ and the eccentricity $e$ as

$$
I_{\mathrm{np}}^{\text {in }}=\frac{I_{\mathrm{s}}}{\pi} \sin \theta\left(1-e^{2}\right)^{-1 / 2}
$$

(Kieffer and Zent 1992), where $I_{\mathrm{s}}=590 \mathrm{~W} \mathrm{~m}^{-2}$ is the solar flux at the average Martian distance from the sun. Since for the last ten million years, the eccentricity has been limited by $0<e<0.12$ (Laskar et al. 2002), it is clear that the influence of the obliquity in Eq. (9) outweighs by far that of the eccentricity, so that we set $e=0$ for simplicity.

Assuming near-steady-state conditions, $I_{\mathrm{np}}^{\text {in }}$ is in balance with the outgoing mean annual longwave radiation, $I_{\mathrm{np}}^{\text {out }}$,

$$
I_{\mathrm{np}}^{\text {in }}(1-A)=I_{\mathrm{np}}^{\text {out }},
$$

where $A$ is the albedo. According to the Stefan-Boltzmann law, the outgoing radiation is

$$
I_{\mathrm{np}}^{\text {out }}=\varepsilon \sigma T_{\mathrm{np}}^{4}
$$

where $\sigma=5.67 \times 10^{-8} \mathrm{~W} \mathrm{~m}^{-2} \mathrm{~K}^{-4}$ is the Stefan-Boltzmann constant, $\varepsilon$ is the emissivity and $T_{\mathrm{np}}$ is the mean annual surface temperature at the north pole. Inserting (11) in (10) 


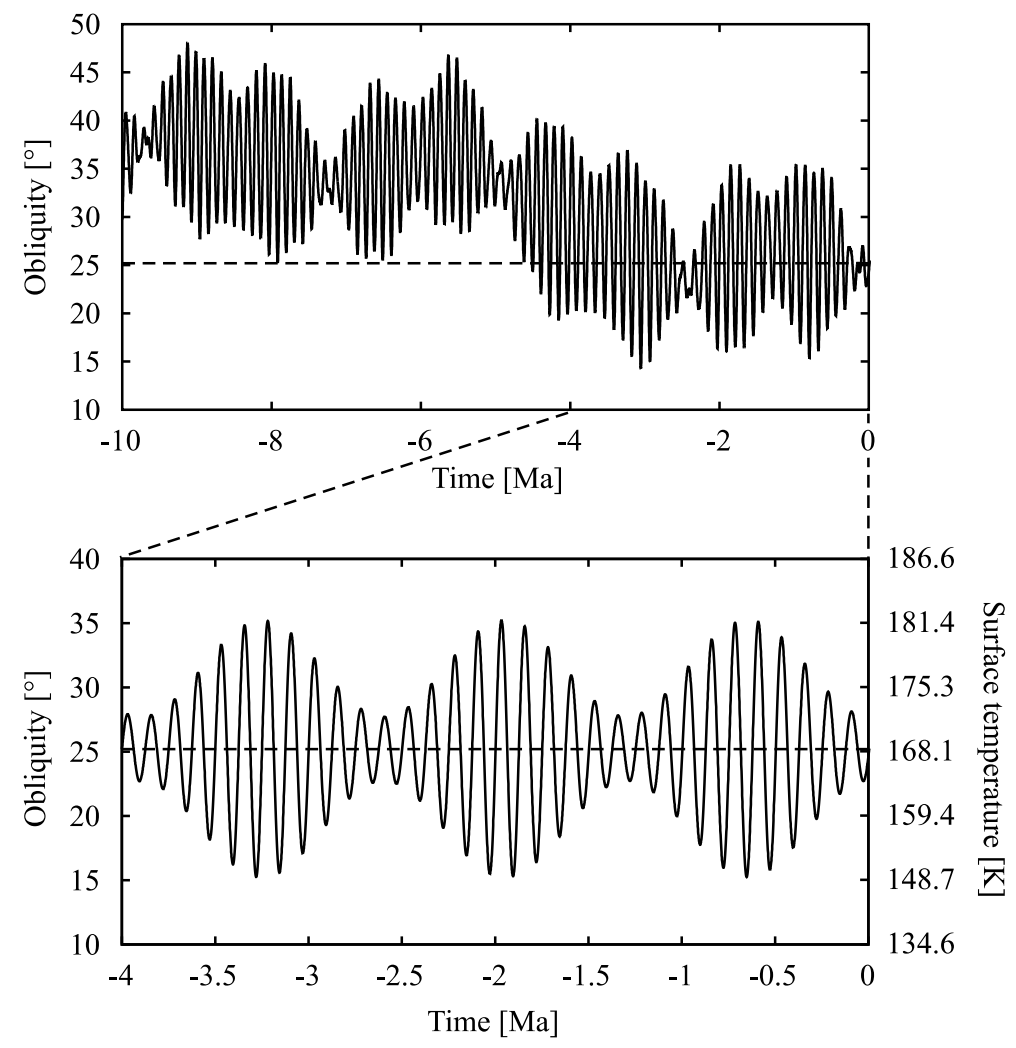

Figure 3: Top: Obliquity $\theta$ by Laskar et al. (2002) for the last ten million years. Bottom: Simplified two-cycle obliquity (left ordinate) and resulting mean-annual surface temperature at the north pole $T_{\mathrm{np}}$ (right ordinate) for the last four million years.

and solving for $T_{\mathrm{np}}$ yields

$$
T_{\mathrm{np}}(t)=\left(\frac{I_{\mathrm{np}}^{\mathrm{in}}(t)(1-A)}{\varepsilon \sigma}\right)^{1 / 4} .
$$

With albedo $A=0.43$ (Thomas et al. 1992), the emissivity $\varepsilon$ taken as unity and the present insolation $I_{\mathrm{np}}^{\text {in }}(0)=79.96 \mathrm{~W} \mathrm{~m}^{-2}$, we obtain the present temperature $T_{\mathrm{np}}(0)=168.4 \mathrm{~K}$. The temperature history, which varies by ca. $30 \mathrm{~K}$ within the considered range of obliquities, is depicted in Fig. 3 (bottom panel, right ordinate axis).

The above albedo and emissivity values are interpreted as long-term averages for the NPC, therefore temporal changes are not accounted for. If we assume an uncertainty of $\Delta A=0.05$ for the albedo and of $\Delta \varepsilon=0.1$ for the emissivity, the terms $(1-A)$ and $1 / \varepsilon$ in Eq. (12) are both afflicted with relative errors of approx. 10\%. According to the rules of error propagation, either of these yield a relative error of $2.5 \%$ for $T_{\mathrm{np}}$. In absolute terms, this is approx. $\pm 4 \mathrm{~K}$ due to the albedo uncertainty and $+4 \mathrm{~K}$ due to the emissivity uncertainty ( $\varepsilon>1$ is of course physically meaningless).

The mean annual surface temperature for an arbitrary position $x, y$ on the polar cap, 
$T_{\mathrm{s}}$, is now prescribed similarly to Greve (2000b) and Greve et al. (2003),

$$
T_{\mathrm{s}}(x, y, t)=T_{\mathrm{np}}(t)+c_{\mathrm{s}} \tilde{\phi}(x, y)
$$

where $\tilde{\phi}$ is the co-latitude and $c_{\mathrm{s}}$ the co-latitude coefficient. In contrast to the earlier studies, we have refrained here from introducing an explicit dependency on elevation by an atmospheric temperature lapse rate. The reason is that the computation of the north-polar surface temperature according to Eq. (12) is based on the idea of a radiation-dominated environment due to the tenuous Martian atmosphere. Because of this, it is consequent to attribute the surface warming off the north pole to the increasing insolation with increasing distance from the north pole (co-latitude), and not to the decreasing surface elevation. Therefore, the warming is parameterized by the co-latitude coefficient only, and as a suitable value $c_{\mathrm{s}}=2.25 \mathrm{~K}\left({ }^{\circ} \mathrm{co}-\mathrm{lat}\right)^{-1}$ is chosen. Note that the surface-temperature parametrization described by Eqs. (12) and (13) is not influenced directly by atmospheric pressure variations.

\subsection{Accumulation-ablation rate}

The accumulation rate $a_{\text {sat }}^{+}$("saturation accumulation") over the north-polar cap is assumed to be proportional to the water-vapour saturation pressure in the atmosphere $p_{\text {sat }}$, which is given by the Clausius-Clapeyron relation (e.g. Müller 2001),

$$
a_{\text {sat }}^{+}(t) \propto p_{\text {sat }}(t) \propto \exp \left(-\frac{\lambda}{R_{\mathrm{m}} T_{\mathrm{ref}}(t)}\right),
$$

with the latent heat $\lambda=\lambda_{\text {sol } \rightarrow \text { liq }}+\lambda_{\text {liq } \rightarrow \text { vap }}=(335+2525) \mathrm{kJ} \mathrm{kg}^{-1}=2860 \mathrm{~kJ} \mathrm{~kg}^{-1}$ and the gas constant $R_{\mathrm{m}}=R / M_{\mathrm{H}_{2} \mathrm{O}}=8.314 \mathrm{~J} \mathrm{~mol}^{-1} \mathrm{~K}^{-1} / 18.015 \mathrm{~kg} \mathrm{kmol}^{-1}=461.5 \mathrm{~J} \mathrm{~kg}^{-1} \mathrm{~K}^{-1}$. The atmospheric reference temperature for the north-polar region $T_{\text {ref }}$ is prescribed as

$$
T_{\text {ref }}(t)=T_{\text {ref }}^{0}+\Delta T_{\mathrm{s}}(t)
$$

with the present value $T_{\text {ref }}^{0}=173 \mathrm{~K}$ and the surface-temperature offset

$$
\Delta T_{\mathrm{s}}(t)=T_{\mathrm{np}}(t)-T_{\mathrm{np}}(0)
$$

With the present accumulation rate $a_{\text {sat, }, 0}^{+}$, Eqs. (14) and (15) yield

$$
a_{\mathrm{sat}}^{+}(t)=a_{\mathrm{sat}, 0}^{+} \exp \left(\frac{\lambda}{R_{\mathrm{m}} T_{\mathrm{ref}}^{0}}-\frac{\lambda}{R_{\mathrm{m}} T_{\mathrm{ref}}(t)}\right),
$$


which is depicted in Fig. 4. Based on different methods [amount of water vapour in the atmosphere, shortage of craters, mass-balance modelling; see discussion and references in Greve (2000b)], $a_{\text {sat }, 0}^{+}$has been estimated to be of the order of $0.1 \mathrm{~mm}$ w.e. $\mathrm{a}^{-1}$ - w.e. denoting water equivalent -, with an uncertainty of a factor ten in either direction. Further, it is not clear whether $\mathrm{H}_{2} \mathrm{O}$-ice accumulation takes place mainly as snowfall, or mainly as direct condensation at the surface. However, the form of accumulation is of no importance for our simulations.

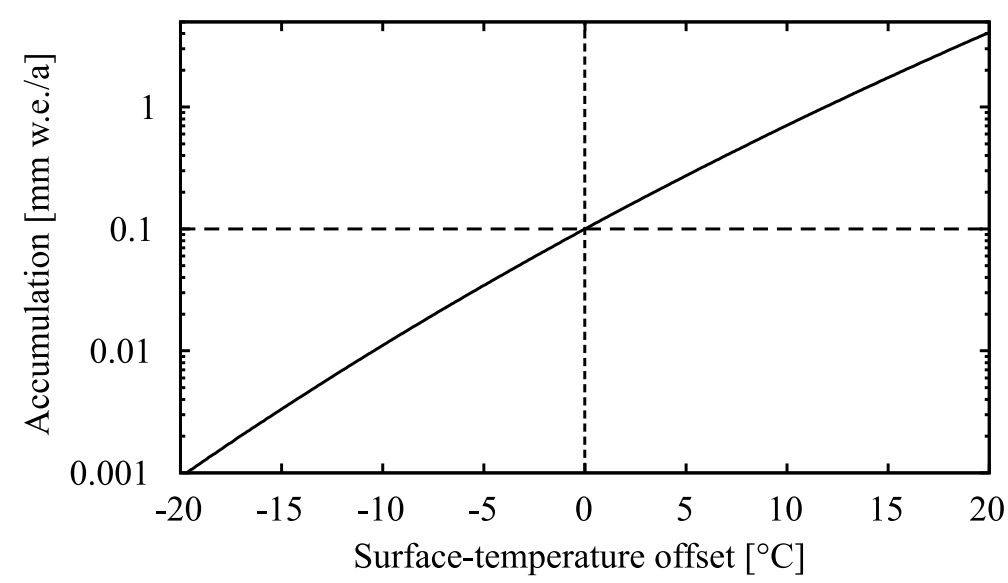

Figure 4: Accumulation rate $a_{\text {sat }}^{+}$as a function of surface-temperature offset $\Delta T_{\mathrm{s}}$, for present value $a_{\text {sat }, 0}^{+}=0.1 \mathrm{~mm}$ w.e. $\mathrm{a}^{-1}$.

For the net mass balance, that is, the accumulation-ablation rate $a_{\text {net }}=a_{\text {sat }}^{+}-a^{-}\left(a^{-}\right.$: ablation rate), we propose an equilibrium-line concept dependent on the horizontal distance from the north pole, $d$. This is a widely-used approach for terrestrial ice-sheet and glacier problems, and we employ it in the variant of the ice-sheet-modelling intercomparison study by Payne et al. (2000). It is given by

$$
a_{\mathrm{net}}(x, y, t)=\min \left[a_{\mathrm{sat}}^{+}(t), g(t) \times\left(d_{\mathrm{el}}(t)-d(x, y)\right)\right],
$$

where $g$ is the accumulation-ablation-rate gradient and $d_{\mathrm{el}}$ the distance of the equilibrium line from the north pole (Fig. 5).

For present conditions, the values of the two parameters $d_{\mathrm{el}}^{0}$ and $g_{0}$ should be chosen such that the equilibrium line is close to the ice margin. The interior of the north-polar cap must lie in the accumulation area where $a_{\text {net }}=a_{\text {sat }, 0}^{+}$. This can be achieved by choosing $d_{\mathrm{el}}^{0}=550 \mathrm{~km}$ and $g_{0}=2.5 \times 10^{-4} \mathrm{~mm}$ w.e. $\mathrm{a}^{-1} \mathrm{~km}^{-1}$. Thus, for $a_{\text {sat }, 0}^{+}=0.1 \mathrm{~mm}$ w.e. $\mathrm{a}^{-1}$ the accumulation area where $a_{\text {net }}=a_{\text {sat }, 0}^{+}$lies within $d \leq 150 \mathrm{~km}$, and the distance from the accumulation area to the equilibrium line is $l_{\mathrm{g}}^{0}=400 \mathrm{~km}$ (Fig. 5). For other times, we 


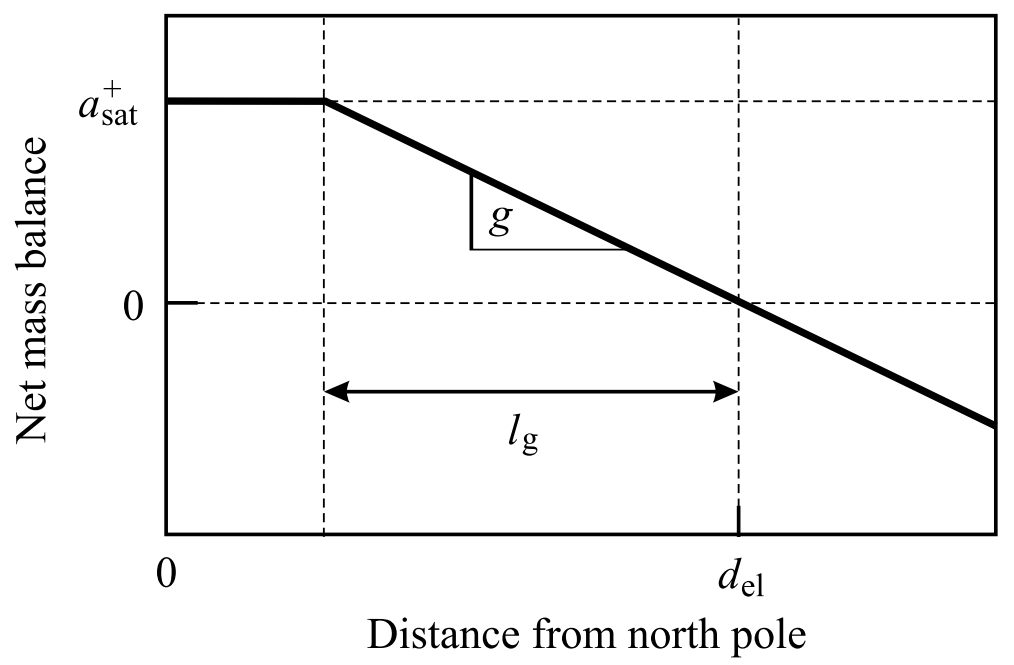

Figure 5: Distance-dependent parametrization of the net mass balance (accumulationablation rate).

assume for simplicity and lack of better knowledge that $d_{\mathrm{el}}$ is unchanged, so that

$$
d_{\mathrm{el}}(t)=d_{\mathrm{el}}^{0}
$$

The gradient $g$ is taken proportional to the accumulation rate,

$$
g(t)=g_{0} \times \frac{a_{\text {sat }}^{+}(t)}{a_{\mathrm{sat}, 0}^{+}}
$$

so that the size of the accumulation area remains constant, and therefore $l_{\mathrm{g}}(t)=l_{\mathrm{g}}^{0}=$ $400 \mathrm{~km}$.

\section{Simulation set-up}

The model domain consists of a $1800 \mathrm{~km} \times 1800 \mathrm{~km}$ square in polar stereographic projection, centered at the pole (Fig. 1). The horizontal resolution is $20 \mathrm{~km}$, the vertical resolution 21 grid points in the cold-ice column, 11 grid points in the temperate-ice column (if existing) and 11 grid points in the lithosphere column.

The ice mechanics is described by Eq. (1) with standard values for the terrestrial Greenland ice sheet, $n=3$ and $E=3$. This includes the influence of small amounts of fine dust, ca. $1 \mathrm{mg} \mathrm{kg}^{-1}$ with particle sizes of 0.1 to $2 \mu \mathrm{m}$ as it was measured in the Wisconsinice-age part of the ice core Dye 3 in south Greenland (Hammer et al. 1985). This makes the ice more readily deformable than ideally pure ice with $E=1$ (Paterson 1991). However, if major parts of the ice volume were contaminated significantly with dust, the mixture of 
deformable ice and essentially rigid dust would be even stiffer than pure ice. On the other hand, the decreased heat conductivity and the increased density of an ice-dust mixture result in increased basal temperatures and driving stresses, respectively, which both favour ice flow. The combined effect was discussed by Greve et al. (2003), who concluded that dust volume fractions of $\varphi \leq 20 \%$ alter flow velocities by a factor at maximum of two and basal temperatures by less than $5^{\circ} \mathrm{C}$. For larger dust contents the deviations would increase rapidly.

Initial conditions are defined by an ice-free state with isostatically equilibrated ground. Owing to the large average obliquities between ten and five million years ago, it is likely that this was the real situation during this period (Laskar et al. 2002; Forget, pers. comm. 2003; see also Fig. 3). A formation of the present NPC during the last millions of years is also consistent with the results by Herkenhoff and Plaut (2000). Based on the observed absence of craters larger than $300 \mathrm{~m}$ at the surface of the NPC, they estimate a surface age of approx. $100 \mathrm{ka}$ and a resurfacing rate of approx. $1 \mathrm{~km}$ per Ma.

At the ice-bedrock interface, no-slip conditions are applied regardless of the basal temperature. For the geothermal heat flux, the value $q_{\text {geo }}=35 \mathrm{~mW} \mathrm{~m}^{-2}$ is used as standard (Budd et al. 1986, Schubert et al. 1992); this is about 2/3 of the average geothermal heat flux on Earth. The standard value of the fraction of isostatic compensation is chosen as $f_{\text {iso }}=0.65$, approximately $2 / 3$ of full local compensation, which was found to be a likely estimate in the previous study by Greve et al. (2003) where a more sophisticated viscoelastic multi-layer ground model was applied.

As it was mentioned at the beginning of Sect. 3.1, in this study we aim at investigating the evolution and dynamic response of the NPC under simplified, idealized conditions, rather than employing the real, complex climatic forcing with a whole spectrum of frequencies. Therefore, two types of simulations are carried out: (i) steady-state simulations for present climate conditions, and (ii) transient simulations over idealized climate cycles. In the steady-state runs, the obliquity is kept constant over time at its present value $\theta_{0}=25.2^{\circ}$. This implies a north-polar surface temperature of $T_{\mathrm{np}}=168.4 \mathrm{~K} \approx-105^{\circ} \mathrm{C}$, and $\Delta T_{\mathrm{s}}(t) \equiv 0$ (Sect. 3.1). For the surface-temperature parametrization (13), we use the co-latitude coefficient $c_{\mathrm{s}}=2.25 \mathrm{~K}\left({ }^{\circ} \text { co-lat }\right)^{-1}$. Standard settings for the parameters in the accumulation-ablation model are $a_{\text {sat }}^{+}=0.1 \mathrm{~mm}$ w.e. $\mathrm{a}^{-1}, d_{\mathrm{el}}=550 \mathrm{~km}$ and $g=2.5 \times 10^{-4} \mathrm{~mm}$ w.e. $\mathrm{a}^{-1} \mathrm{~km}^{-1}$. In order to assess the influence of the several parameters on the dynamics of the NPC, additional simulations are run with varied parameters; see Table 2. All steady-state simulations are integrated with a time-step of $10 \mathrm{ka}$ for $500 \mathrm{Ma}$ until the dynamic and thermodynamic equilibrium.

For the transient runs, we use the simplified two-cycle obliquity forcing of Sect. 3.1. Like for the steady-state simulations, the standard run has the surface-temperature parameter 


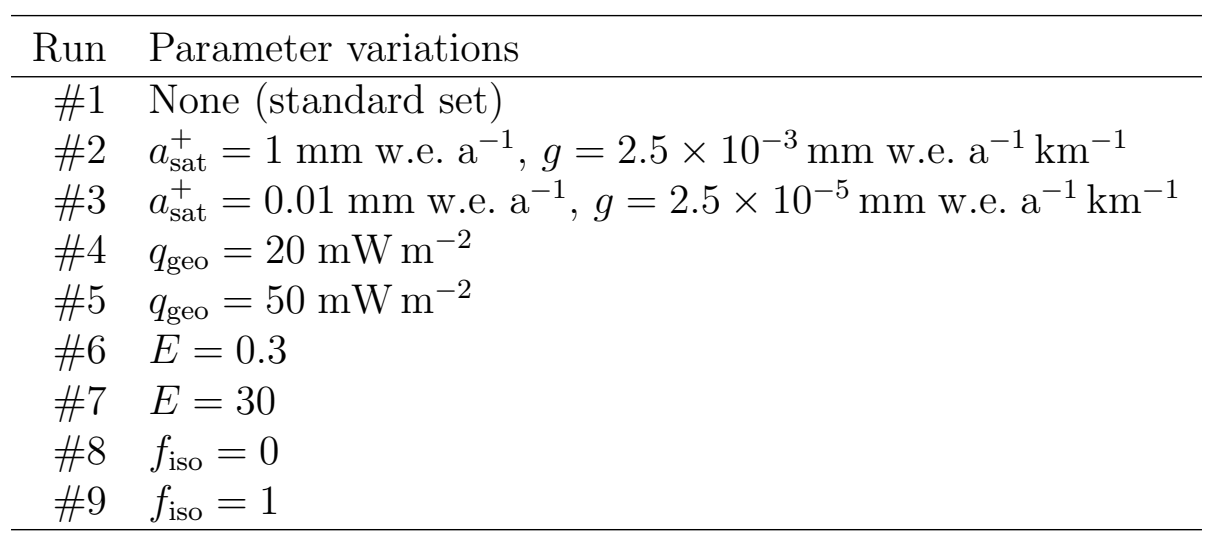

Table 2: Set-up for the steady-state simulations.

$c_{\mathrm{s}}=2.25 \mathrm{~K}\left({ }^{\circ}{ }^{\mathrm{co}-l a t}\right)^{-1}$, and the accumulation-ablation parameters $a_{\mathrm{sat}, 0}^{+}=0.1 \mathrm{~mm} \mathrm{w} \cdot \mathrm{e} . \mathrm{a}^{-1}$, $d_{\mathrm{el}}^{0}=550 \mathrm{~km}, g_{0}=2.5 \times 10^{-4} \mathrm{~mm}$ w.e. $\mathrm{a}^{-1} \mathrm{~km}^{-1}$. The transient standard run starts from ice-free conditions as the steady-state simulations. An additional run is conducted that uses the present MOLA topography as initial condition. Both simulations are integrated with a time-step of 5 ka over 100 Ma.

\section{Results and discussion}

\subsection{Steady-state runs}

The evolution of the total ice volume, $V_{\text {tot }}$, and the ice-covered area, $A$, are shown in Fig. 6 for the standard steady-state run. Over the first $100 \mathrm{Ma}$, the ice volume increases essentially linearly. The steady-state value, $5.62 \times 10^{6} \mathrm{~km}^{3}$, is reached after $250 \mathrm{Ma}$. The ice-covered area shows a slightly different behaviour. Over the first $50 \mathrm{Ma}$, it remains essentially constant at $1.00 \times 10^{6} \mathrm{~km}^{2}$, the size of the area with a positive surface mass balance (accumulation-ablation rate). Then, the area starts to increase, because due to increasing ice flow the ice cap spreads into the ablation zone. Finally, at ca. $250 \mathrm{Ma}$, the steady-state value of $2.19 \times 10^{6} \mathrm{~km}^{2}$ is reached. Both the steady-state volume and area are much larger than the respective values of the present ice cap, which are estimated as $V_{\text {tot }}=1.2 \ldots 1.7 \times 10^{6} \mathrm{~km}^{3}$ and $A_{\mathrm{i}, \mathrm{b}}=10^{6} \mathrm{~km}^{2}$ from the MOLA topography. Further, since the real Martian climate will not have been constant over a period as long as $250 \mathrm{Ma}$ regarding the much shorter obliquity cycles, it is clear that the NPC cannot be expected to be in a steady state.

Therefore, we define the build-up time for the present cap, $t_{\text {build }}$, as the time the NPC requires to reach the MOLA value for the present maximum surface elevation, $h_{\max }=$ $-1.95 \mathrm{~km}$ (with respect to the reference geoid), when starting from ice-free conditions. 

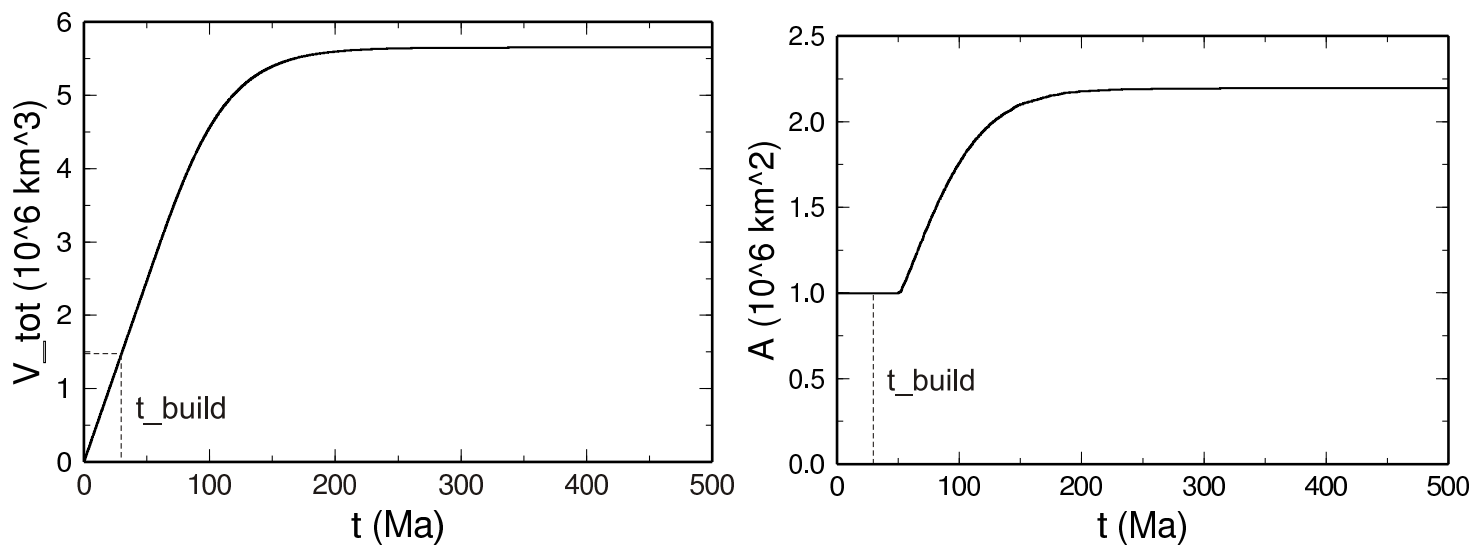

Figure 6: Standard steady-state simulation: Total ice volume $V_{\text {tot }}$ and ice-covered area $A$ as functions of time $t$. The build-up time $t_{\text {build }}=29.66 \mathrm{Ma}$ (see main text) is indicated in both panels.

For the standard steady-state run, $t_{\text {build }}=29.66$ Ma. Fig. 7 shows the simulated surface topography, surface velocity and basal temperature for $t=t_{\text {build }}$. The large-scale shape of the simulated ice cap agrees well with that of the MOLA topography (Fig. 1, left panel). More detailed structures like Chasma Borealis, the canyon cutting through the western part of the cap, or the spiralling scarps and troughs are not reproduced. This is so because our schematic climatic forcing does not include any feedback mechanisms of initial topography or surface-albedo perturbations on ablation, which are required to form such structures and keep them open over time (Fisher 1993, Hvidberg 2003).

The maximum ice-flow velocity is $1.162 \mathrm{~mm} \mathrm{a}^{-1}$, four to five orders of magnitude less than for terrestrial ice sheets. The velocity is slightly larger in the western than in the eastern hemisphere (note the shape of the contour for $1 \mathrm{~mm} \mathrm{a}^{-1}$ ) because in the west the bedrock elevations are lower, hence the ice thicknesses are higher. Basal temperatures nowhere exceed $-65^{\circ} \mathrm{C}$ so that temperate ice and liquid water cannot occur anywhere in the ice cap. As already stated above, the steady-state topography, which is reached for $t \geq 250 \mathrm{Ma}$ (also depicted in Fig. 7), shows a much larger ice cap than the present one.

The results of the parameter studies (Table 2) are summarized in Figs. 8 and 9. The build-up time $t_{\text {build }}$ (Fig. 8) is mainly sensitive to the saturation accumulation $a_{\text {sat }}^{+}$which determines directly the ice-cap growth. The slow ice flow does not influence the build-up times significantly, so that the static relation $t_{\text {build }} \propto 1 / a_{\text {sat }}^{+}$holds approximately. Strong variations of the geothermal heat flux $q_{\text {geo }}$ and the flow-enhancement factor $E$, which have a pronounced influence on the ice flow (Fig. 9), only alter the build-up time by a few percent. More important is the effect of the fraction of isostatic compensation $f_{\text {iso }}$, which is varied over the full possible range between no (0\%) and full (100\%) compensation. This is because, with increasing isostatic compensation, the build-up of the NPC requires an 

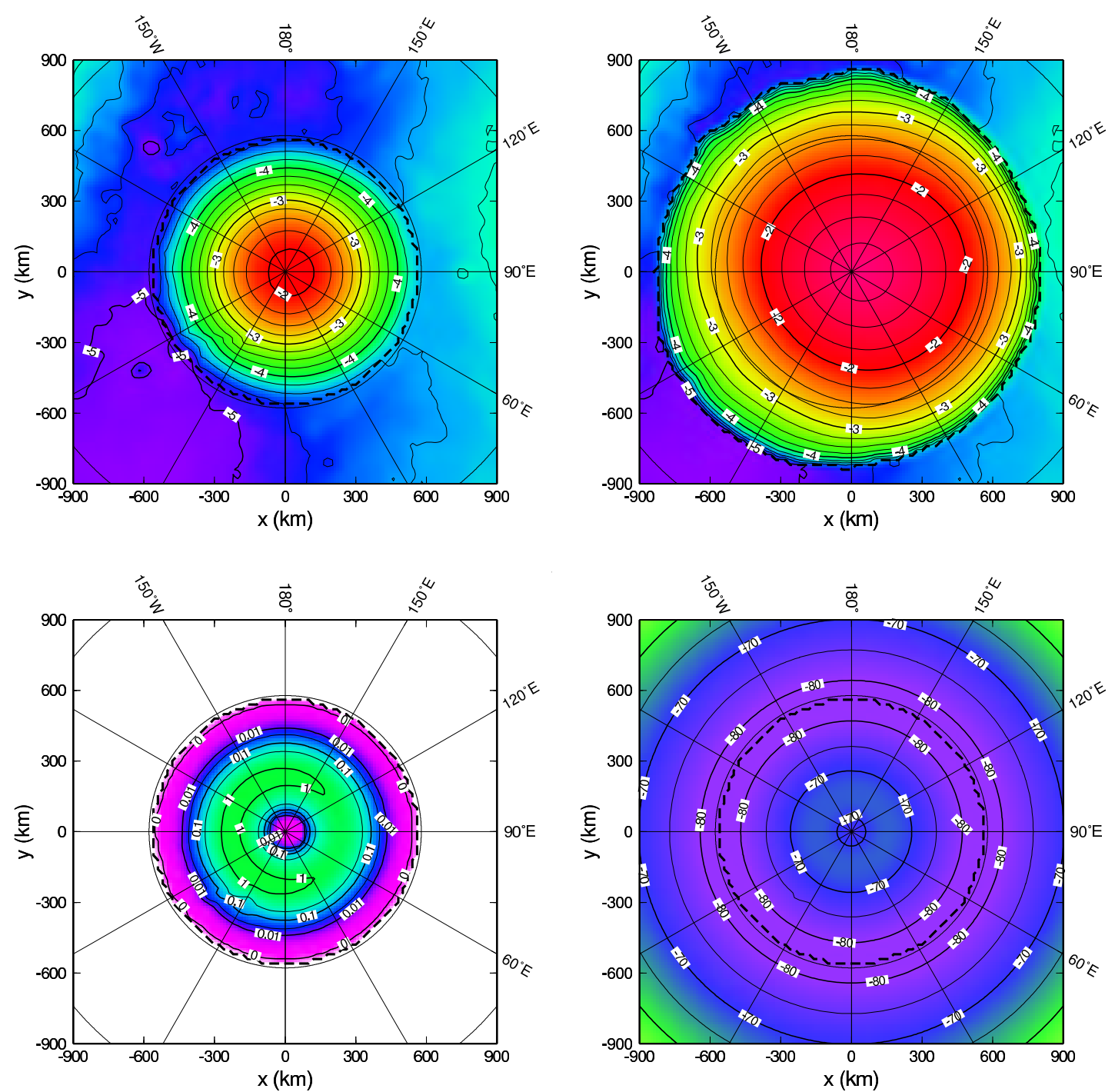

Figure 7: Standard steady-state simulation. Top left: Surface topography for $t_{\text {build }}=$ $29.66 \mathrm{Ma}$ (in $\mathrm{km}$ relative to the reference geoid). Top right: Surface topography for $t_{\text {final }}=500 \mathrm{Ma}$ (in $\mathrm{km}$ relative to the reference geoid). Bottom left: Surface velocity for $t_{\text {build }}=29.66 \mathrm{Ma}\left(\right.$ in $\mathrm{mm} \mathrm{a}^{-1}$ ). Bottom right: Basal temperature relative to pressure melting for $t_{\text {build }}=29.66 \mathrm{Ma}\left(\right.$ in $\left.{ }^{\circ} \mathrm{C}\right)$. In all panels, heavy-dashed lines indicates the ice margin. 

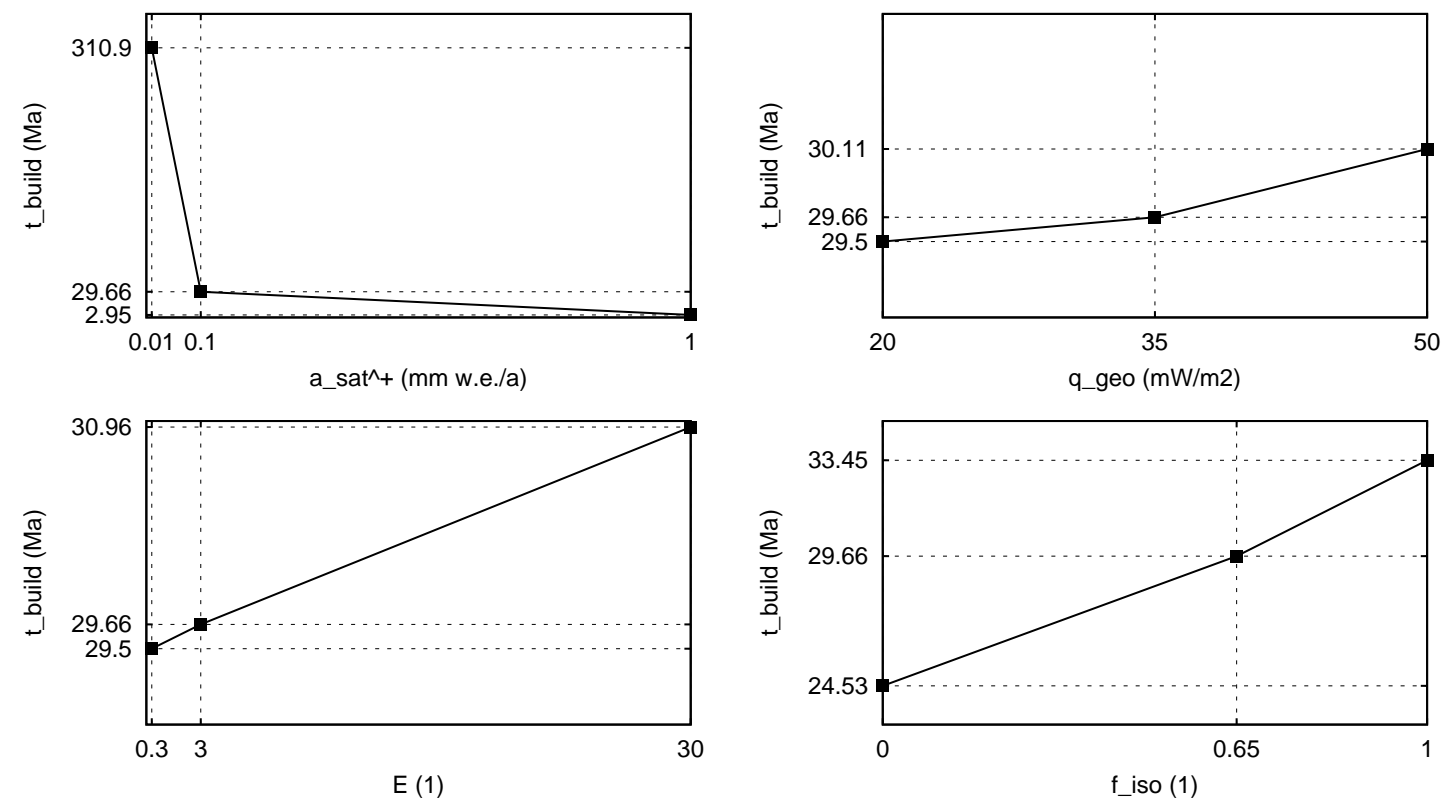

Figure 8: Steady-state simulations: Build-up time $t_{\text {build }}$ as a function of the saturation accumulation $a_{\text {sat }}^{+}$, the geothermal heat flux $q_{\text {geo }}$, the flow-enhancement factor $E$ and the fraction of isostatic compensation $f_{\text {iso }}$.
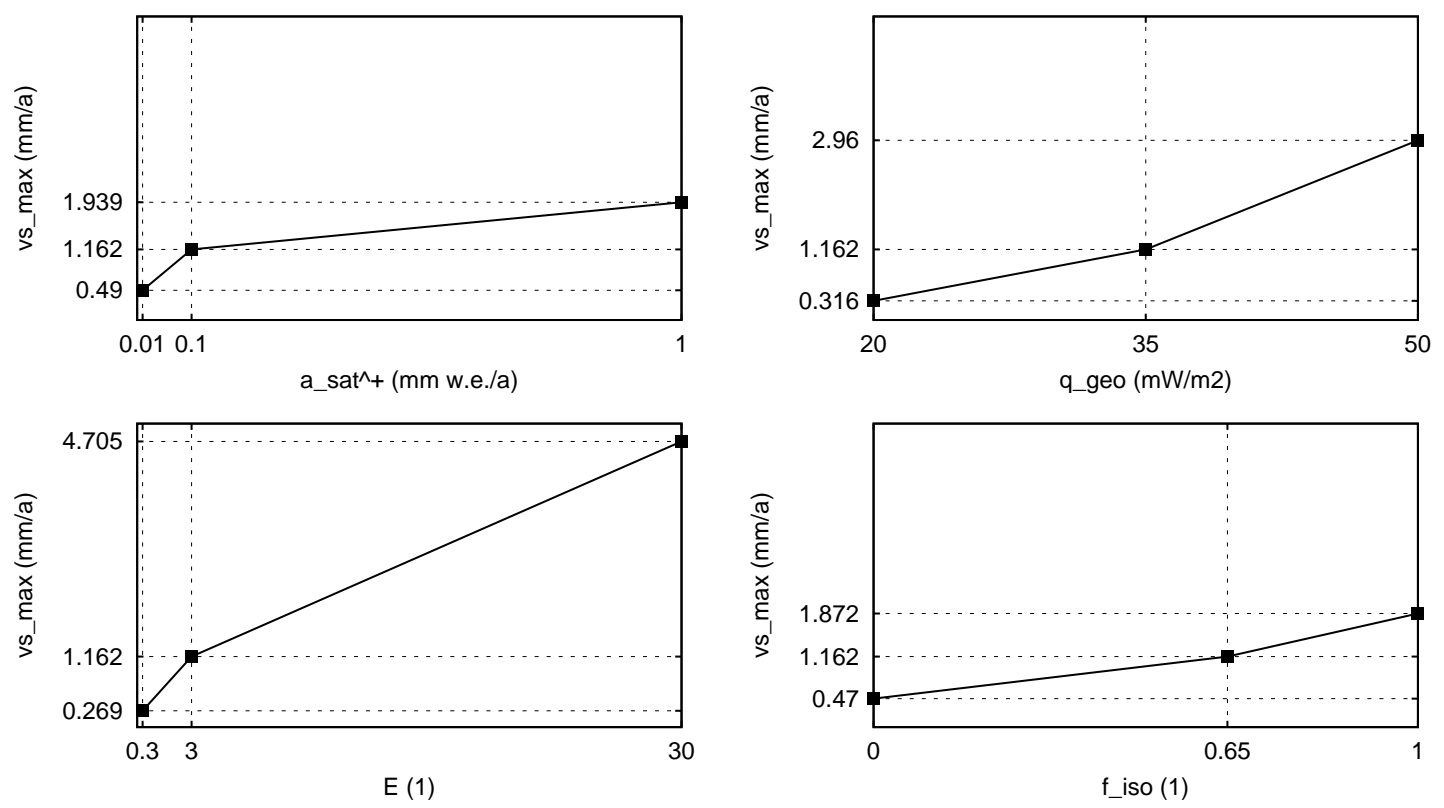

Figure 9: Steady-state simulations: Maximum surface velocity $v_{\mathrm{s}, \max }$ as a function of the saturation accumulation $a_{\text {sat }}^{+}$, the geothermal heat flux $q_{\text {geo }}$, the flow-enhancement factor $E$ and the fraction of isostatic compensation $f_{\text {iso }}$.

increasing ice thickness. In contrast to the build-up times, the maximum surface velocities $v_{\mathrm{s}, \max }$ (Fig. 9) react sensitively to variations of all the investigated parameters. However, in all cases they fall in the interval between $0.25 \mathrm{~mm} \mathrm{a}^{-1}$ and $5 \mathrm{~mm} \mathrm{a}^{-1}$, which is still small 
in absolute terms.

The effect of the uncertainty in surface albedo and emissivity can be estimated as follows. With the values given in Sect. 3.1, it was found that these uncertainties lead to surface-temperature uncertainties of approx. $4 \mathrm{~K}$. Since the time-scale for heat conduction is much shorter than the determined build-up times, this error propagates essentially undamped down into the ice cap. An ice-temperature uncertainty of $4 \mathrm{~K}$ entails an uncertainty of the rate factor (2) of about a factor two, and consequently ice-flow velocities are affected by a factor two as well. This is comparable to the effect of the varied geothermal heat flux (Fig. 9), which also changes the ice temperature and therefore speeds up or slows down the ice flow.

\subsection{Transient runs}

Similar to Fig. 6 for the standard steady-state run, the evolution of the total ice volume, $V_{\text {tot }}$, and the ice-covered area, $A$, are shown in Fig. 10 for the standard transient run. It is striking that both curves resemble very much those of the steady-state run, variations due to the obliquity cycles are barely recognizable. Therefore, the evolution of $V_{\text {tot }}$ and $A$ is mainly governed by the long-term average climate. This contradicts the approach made in the previous studies by Greve (2000b) and Greve et al. (2003) where it was assumed that the climate cycles cause major variations of the ice-cap topography.
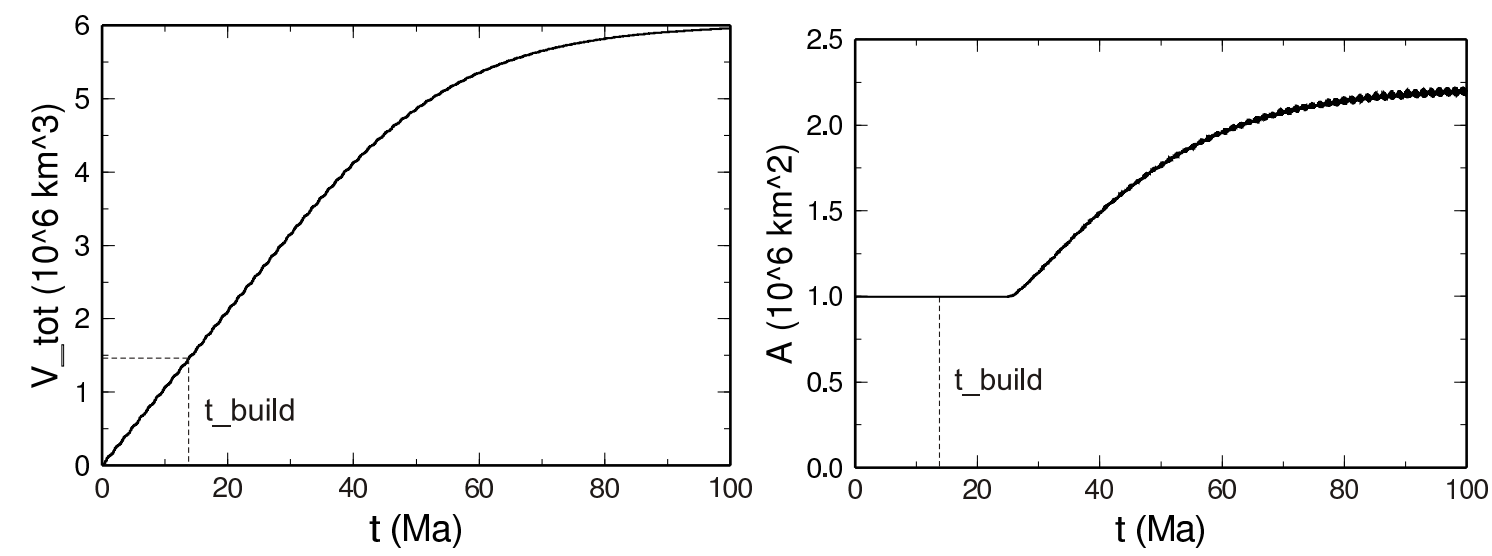

Figure 10: Two-cycle-obliquity simulation starting from ice-free conditions: Total ice volume $V_{\text {tot }}$ and ice-covered area $A$ as functions of time $t$. The build-up time $t_{\text {build }}=13.78 \mathrm{Ma}$ (see main text) is indicated in both panels.

The build-up time for the present cap is $t_{\text {build }}=13.78 \mathrm{Ma}$, as compared to $29.66 \mathrm{Ma}$ for the standard steady-state run. This is due to the fact that the average saturation accumulation is larger than its present value, compare Fig. 4 (note the logarithmic scale). However, this scenario is still unable to build up the present cap within the last five million 
years, which would be required if the large obliquities prior to this time (Fig. 3) led to a north-polar region completely devoid of ice. Therefore, either this assumption is wrong, or the present saturation accumulation must be at least 2.5 times larger than assumed in the simulation, that is, $a_{\text {sat }, 0}^{+} \geq 0.25 \mathrm{~mm}$ w.e. $\mathrm{a}^{-1}$.
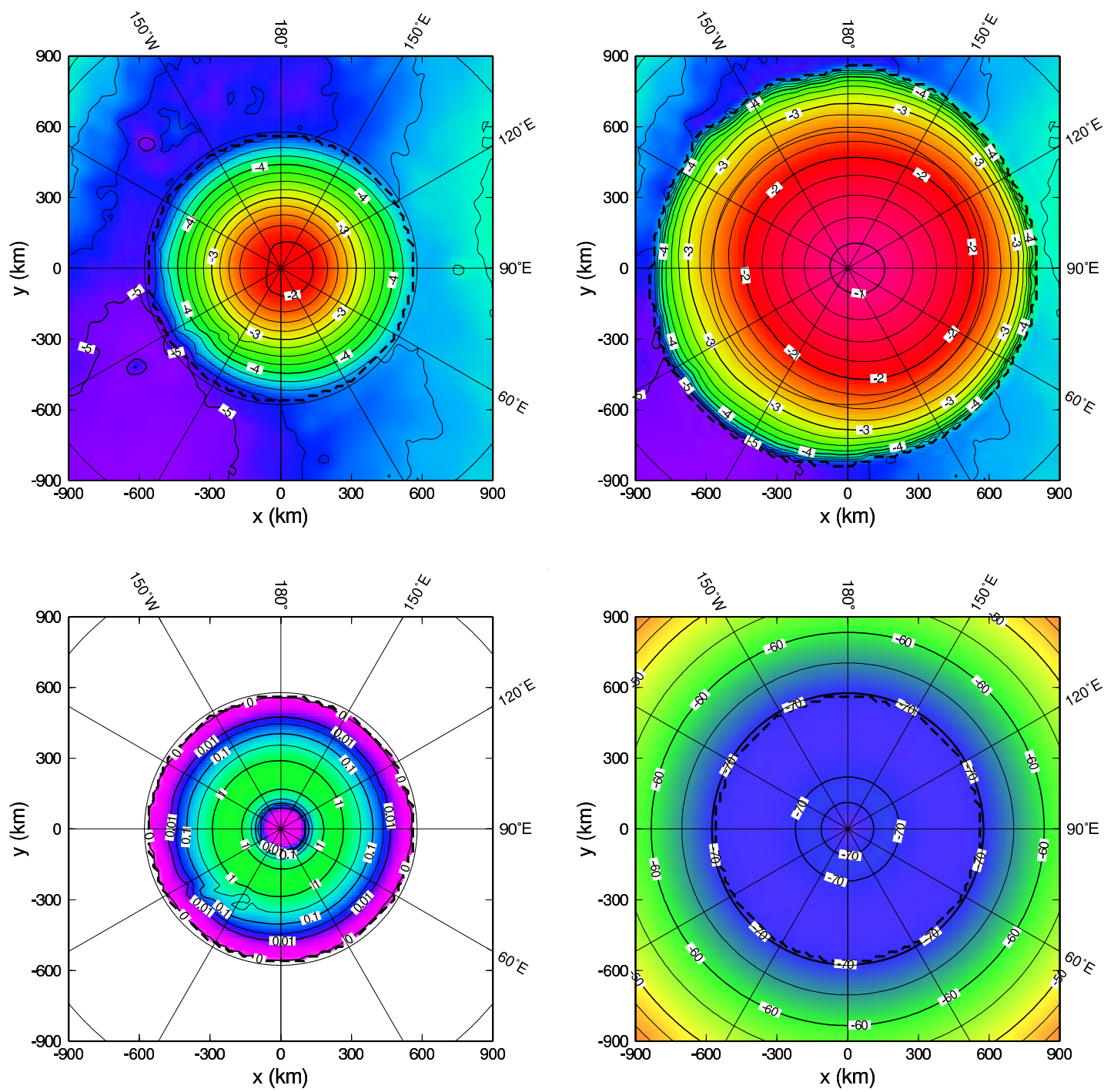

Figure 11: Two-cycle-obliquity simulation starting from ice-free conditions. Top left: Surface topography for $t_{\text {build }}=13.78 \mathrm{Ma}$ (in $\mathrm{km}$ relative to the reference geoid). Top right: Surface topography for $t_{\text {final }}=100 \mathrm{Ma}$ (in $\mathrm{km}$ relative to the reference geoid). Bottom left: Surface velocity for $t_{\text {build }}=13.78 \mathrm{Ma}\left(\right.$ in $\left.\mathrm{mm} \mathrm{a}^{-1}\right)$. Bottom right: Basal temperature relative to pressure melting for $t_{\text {build }}=13.78 \mathrm{Ma}\left(\right.$ in ${ }^{\circ} \mathrm{C}$ ). In all panels, heavy-dashed lines indicate the ice margin.

Fig. 11 depicts the simulated surface topography, surface velocity and basal temperature at $t_{\text {build }}$, as well as the surface topography at the final time of the run, $t_{\text {final }}=100$ Ma. Both topographies are very similar to their counterparts of the steady-state run (Fig. 7), the one for $t_{\text {final }}$ showing slightly larger elevations due to the larger average accumulation 
rate.

The $50 \%$ larger flow velocities $\left(v_{\mathrm{s}, \max }=1.596 \mathrm{~mm} \mathrm{a}^{-1}\right)$ and the up to $10^{\circ} \mathrm{C}$ higher basal temperatures at $t_{\text {build }}$ (which are still far below pressure melting) are due to the fact that at this time the surface-temperature deviation is $\Delta T_{\mathrm{s}}=12.41^{\circ} \mathrm{C}$, which is by chance close to the highest temperature throughout the climate cycles. Only 30 ka earlier, at $t=13.75 \mathrm{Ma}$ when the temperature equals the present one $\left(\Delta T_{\mathrm{s}}=0^{\circ} \mathrm{C}\right)$, the maximum surface velocity is only $v_{\mathrm{s}, \max }=0.588 \mathrm{~mm} \mathrm{a}^{-1}$, thus almost three times smaller.
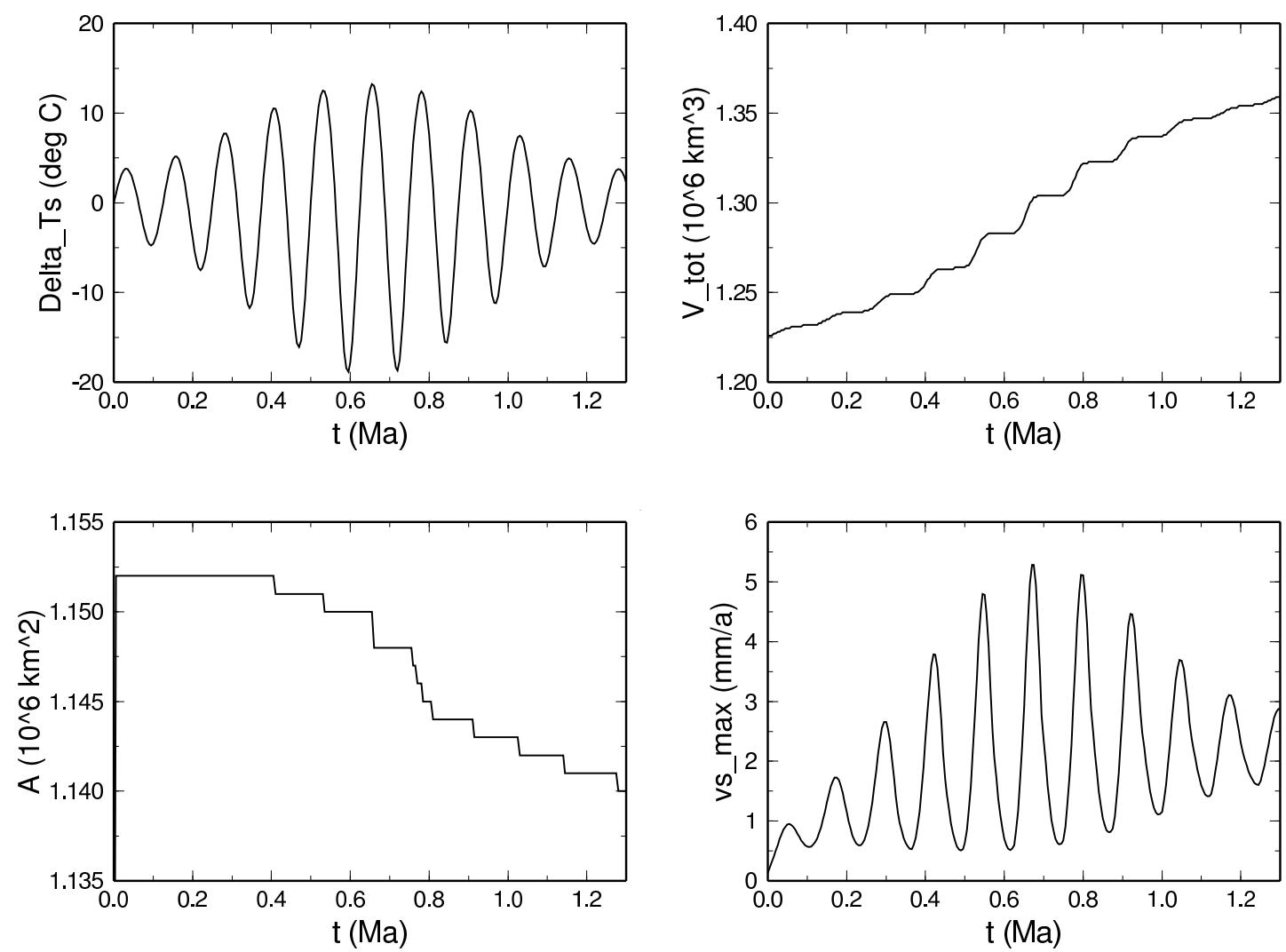

Figure 12: Two-cycle-obliquity simulation starting from present topography: Surfacetemperature deviation $\Delta T_{\mathrm{s}}$, total ice volume $V_{\text {tot }}$, ice-covered area $A$, maximum surface velocity $v_{\mathrm{s}, \max }$ as functions of time $t$ for the first $1.3 \mathrm{Ma}$.

For the transient simulation starting from the MOLA topography, Fig. 12 shows a closeup of the ice-cap evolution over the first 1.3-Ma cycle only. In these graphs, the influence of the climatic variations on the ice volume and area can be noted and reveals that the ice cap is almost stagnant at periods with low surface temperatures, whereas it shows the largest changes in volume and area at periods with high temperatures. Nevertheless, the absolute values of these changes are small compared to the longer-term trends. By contrast, the surface velocity oscillates by a factor of ten, between approximately $v_{\mathrm{s}, \max }=0.5 \mathrm{~mm} \mathrm{a}^{-1}$ and $v_{\mathrm{s}, \max }=5 \mathrm{~mm} \mathrm{a}^{-1}$, maximum velocities following maximum temperatures and vice 
versa.

Finally, a sequence of surface topographies at intervals of $1 \mathrm{Ma}$ is presented in Fig. 13. The simulated growth of the ice cap, first in volume, later also in area, is clearly visible. This is accompanied by a smoothing of small- and medium-scale surface structures under the influence of the zonally averaged forcing. After $10 \mathrm{Ma}$, only a small remnant of Chasma Borealis has survived, and after $20 \mathrm{Ma}$ it has vanished completely. The final state for $100 \mathrm{Ma}$ is essentially the same as that for the standard steady-state run (Fig. 11), implying that the system has lost the memory of its initial conditions at that time.

Note that the above-determined closure time for Chasma Borealis of $\sim 10 \mathrm{Ma}$ is only a theoretical value which excludes any feedbacks of the chasm on local meteorological conditions. In reality, it is expected that the chasm creates a major modification of the local wind circulation pattern by canalizing strong katabatic winds, which affect ice accumulation and ablation processes and lead to enhanced erosion. Further, the lower albedo of the chasm inevitably leads to higher surface temperatures and increased sublimation rates. These feedbacks work against the ice flow and may keep the chasm open for an indefinite period.

Hvidberg (2003) and Hvidberg and Zwally (2003) used a similar ice-flow model and simulated the topography evolution of the NPC in 2-d (radial distance, elevation) and high spatial resolution along MOLA tracks, with a focus on the spiralling troughs. They report that in the absence of any accumulation or ablation, closure times of the troughs due to ice flow are in the range of $100 \mathrm{ka}$ to $1 \mathrm{Ma}$. This result fits well to our value for the much larger Chasma Borealis, which was not considered in their study. They also report strongly enhanced ice-flow velocities of up to $50 \mathrm{~mm} \mathrm{a}^{-1}$ at the steepest scarps, minimum local sublimation rates of $50 \mathrm{~mm} \mathrm{a}^{-1}$ required to keep the troughs open in time and inward-migration speeds of the troughs of tens of centimeters per year.

Fishbaugh and Head (2002) discussed possible formation mechanisms of Chasma Borealis. Based on an analysis of high-resolution MOLA data and Mars Orbiter Camera (MOC) and Viking images of the region, they favoured a formation scenario by meltwater outflow (probably in a jökulhlaup-type event) with subsequent shaping by sublimation and eolian processes. As possible causes for basal melting, they list the following points: "(1) much thicker caps, (2) climate change, (3) obliquity change, (4) subcap volcanic eruptions, (5) the presence of a groundwater mound that reaches the cap base, (6) frictional melting due to cap movement, (7) higher geothermal heat gradient in the past, (8) inclusion of dust, salts, clathrates, etc., to modify the melting point, and (9) polar wander." Point (1) is not consistent with the results of the standard transient run (our most realistic scenario for the geologically recent past of the NPC); see Fig. 10. Points (2), (3) and (6) are accounted for in the simulation and do not raise the basal temperature above $-65^{\circ} \mathrm{C}$ at any time 

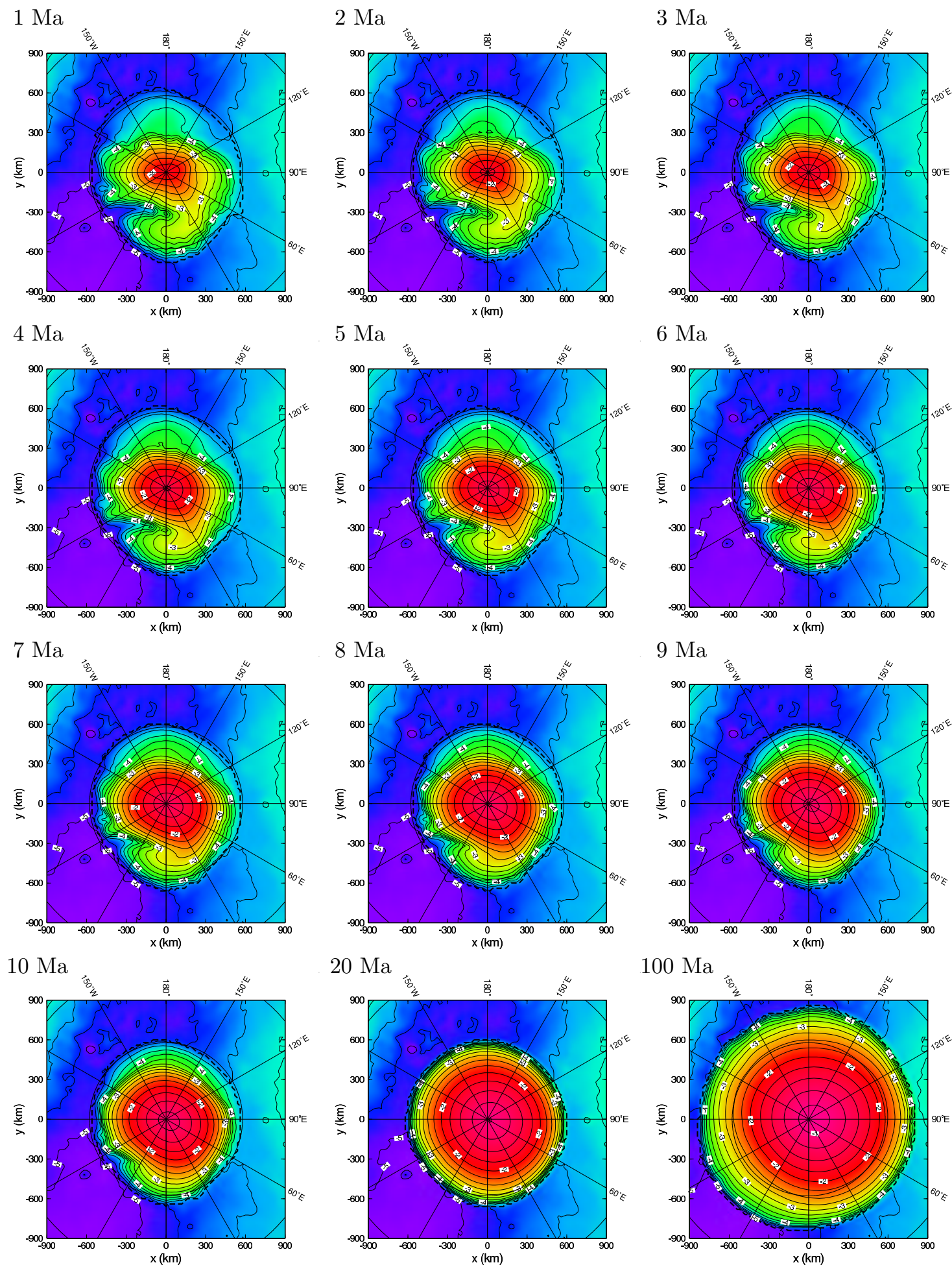

Figure 13: Two-cycle-obliquity simulation starting from present topography: Surface topography for $t=1,2,3,4,5,6,7,8,9,10,20,100 \mathrm{Ma}$ (in $\mathrm{km}$ relative to the reference geoid). In all panels, heavy-dashed lines indicate the ice margin. 
during the modelled NPC history, so they are inconsistent with our results as well. For the same reason, point (5) is unlikely. Further, if the NPC was formed in the last millions of years (geologically the very recent past), significant changes in the average geothermal heat flow (point 7) and polar wander (point 9) are equally unlikely. Therefore, as possible causes for meltwater production consistent with our results remain (i) basal warming and melting-point lowering due to mixed-in dust and salts, and (ii) a temporary heat source under the ice due to a tectono-thermal event or a volcanic eruption.

\section{Summary and outlook}

The main findings of this study are:

- The newly developed Mars Atmosphere-Ice Coupler MAIC provides simple parameterizations for the climatic input surface temperature and accumulation-ablation rate required for prognostic simulations of the NPC, driven mainly by the Milanković parameter obliquity.

- It is very unlikely that the present NPC is in steady state with the present climate, because this would require some $100 \mathrm{Ma}$ of essentially unchanged conditions.

- The present large-scale topography of the NPC is mainly controlled by the history of the surface mass balance. Ice flow, with flow velocities of the order of $1 \mathrm{~mm} \mathrm{a}^{-1}$, plays only a minor role.

- The main obliquity cycles of $125 \mathrm{ka}$ and $1.3 \mathrm{Ma}$ are virtually not reflected in the evolution of the topography of the NPC, which responds mainly to the long-term average climate conditions. By contrast, the ice flow shows a strong variation over the obliquity cycles.

- In order to build up the present cap from ice-free conditions at five million years before present (which is a possible scenario due to the $25^{\circ}-45^{\circ}$ obliquities prior to this time), a present accumulation rate of $\geq 0.25 \mathrm{~mm}$ w.e. $\mathrm{a}^{-1}$ is required.

- In the absence of any counteracting mechanisms like differential ablation or erosion, the closure time for the canyon Chasma Borealis is of the order of 10 Ma.

- For all simulations and all times, basal temperatures are far below pressure melting. This result is very robust and was already reported in the previous studies by Greve (2000b) and Greve et al. (2003). 
For the future, we plan to run simulations driven directly by the history of Martian obliquity and eccentricity over the last ten million years by Laskar et al. (2002). The coupling between the atmosphere and the ice cap will be refined by downscaling simulation results obtained with the atmosphere model PUMA-2 (Portable University Model of the Atmosphere, Fraedrich et al. 2003; see also http://puma.dkrz.de/puma/) adapted to Martian conditions (Segschneider et al. 2004, Planet. Space Sci., submitted for publication). This will further improve the physical basis of the parameterizations for the surface temperature and the accumulation-ablation rate. Moreover, a study is on the way in order to investigate in more detail the influence of the ice rheology and the dust content under the conditions of the NPC (Greve and Mahajan, paper in preparation).

\section{Acknowledgements}

The constructive reviews of this paper by J. Eluskiewicz and N. Mangold are gratefully acknowledged. This work was supported by the Priority Programme 1115 "Mars and the Terrestrial Planets" of the German Research Foundation (Deutsche Forschungsgemeinschaft, DFG) under project nos. KE 226/8, GR 1557/4.

\section{References}

Budd, W. F., D. Jenssen, J. H. I. Leach, I. N. Smith and U. Radok. 1986. The north polar ice cap of Mars as a steady-state system. Polarforsch., 56 (1/2), 43-46.

Byrne, S. and B. C. Murray. 2002. North polar stratigraphy and the paleo-erg of Mars. J. Geophys. Res., 107 (E6), 5044. doi:10.1029/2001JE001615.

Fishbaugh, K. E. and J. W. Head. 2002. Chasma Boreale, Mars: Topographic characterization from Mars Orbiter Laser Altimeter data and implications for mechanisms of formation. J. Geophys. Res., 107 (E3), 5013. doi:10.1029/2000JE001351.

Fisher, D. A. 1993. If Martian ice caps flow - ablation mechanisms and appearance. Icarus, 105 (2), 501-511.

Fraedrich, K., E. Kirk, U. Luksch and F. Lunkeit. 2003. Ein Zirkulationsmodell für Forschung und Lehre. Promet, 29 (1-4), 34-48.

Greve, R. 2000a. Large-scale glaciation on Earth and on Mars. Electronic Publications Darmstadt No. 816, http://elib.tu-darmstadt.de/diss/000816/. Habilitation thesis, Department of Mechanics, Darmstadt University of Technology, Germany. 
Greve, R. 2000b. Waxing and waning of the perennial north polar $\mathrm{H}_{2} \mathrm{O}$ ice cap of Mars over obliquity cycles. Icarus, 144 (2), 419-431. doi:10.1006/icar.1999.6291.

Greve, R. 2001. Glacial isostasy: Models for the response of the Earth to varying ice loads. In: B. Straughan, R. Greve, H. Ehrentraut and Y. Wang (Eds.), Continuum Mechanics and Applications in Geophysics and the Environment, pp. 307-325. Springer, Berlin etc.

Greve, R., V. Klemann and D. Wolf. 2003. Ice flow and isostasy of the north polar cap of Mars. Planet. Space Sci., 51 (3), 193-204. doi:10.1016/S0032-0633(02)00206-4.

Hammer, C. U., H. B. Clausen, W. Dansgaard, A. Neftel, P. Kristinsdottir and E. Johnson. 1985. Continuous impurity analysis along the Dye 3 deep core. In: C. C. Langway, H. Oeschger and W. Dansgaard (Eds.), Greenland Ice Core: Geophysics, Geochemistry and the Environment, Geophysical Monographs No. 33, pp. 90-94. American Geophysical Union, Washington DC.

Herkenhoff, K. E. and J. J. Plaut. 2000. Surface ages and resurfacing rates of the polar layered deposits on Mars. Icarus, 144 (2), 243-253.

Hvidberg, C. S. 2003. Relationship between topography and flow in the north polar cap on Mars. Ann. Glaciol., 37, 363-369.

Hvidberg, C. S. and H. J. Zwally. 2003. Sublimation of water from the north polar cap of Mars. Abstract, Workshop "Mars Atmosphere Modelling and Observations", Granada, Spain, 13-15 Jan. 2003.

Johnson, C. L., S. C. Solomon, J. W. Head, R. J. Phillips, D. E. Smith and M. T. Zuber. 2000. Lithospheric loading by the northern polar cap on Mars. Icarus, 144 (2), 313-328.

Kieffer, H. H. and A. P. Zent. 1992. Quasi-periodic climate change on Mars. In: H. H. Kieffer, B. M. Jakosky, C. W. Snyder and M. S. Matthews (Eds.), Mars, pp. 1180-1218. University of Arizona Press, Tucson.

Laskar, J., B. Levrard and J. F. Mustard. 2002. Orbital forcing of the martian polar layered deposits. Nature, 419 (6905), 375-377.

Le Meur, E. and P. Huybrechts. 1996. A comparison of different ways of dealing with isostasy: examples from modelling the Antarctic ice sheet during the last glacial cycle. Ann. Glaciol., 23, 309-317.

Müller, I. 2001. Grundzüge der Thermodynamik mit historischen Anmerkungen. Springer, Berlin etc., 3rd ed. 
Paterson, W. S. B. 1991. Why ice-age ice is sometimes "soft". Cold Reg. Sci. Technol., 20 (1), 75-98.

Paterson, W. S. B. 1994. The Physics of Glaciers. Pergamon Press, Oxford etc., 3rd ed.

Payne, A. J., P. Huybrechts, A. Abe-Ouchi, R. Calov, J. L. Fastook, R. Greve, S. J. Marshall, I. Marsiat, C. Ritz, L. Tarasov and M. P. A. Thomassen. 2000. Results from the EISMINT model intercomparison: the effects of thermomechanical coupling. $J$. Glaciol., 46 (153), 227-238.

Schubert, G., S. C. Solomon, D. L. Turcotte, M. J. Drake and N. H. Sleep. 1992. Origin and thermal evolution of Mars. In: H. H. Kieffer, B. M. Jakosky, C. W. Snyder and M. S. Matthews (Eds.), Mars, pp. 147-183. University of Arizona Press, Tucson.

Smith, D. E., M. T. Zuber, S. C. Solomon, R. J. Phillips, J. W. Head, J. B. Garvin, W. B. Banerdt, D. O. Muhleman, G. H. Pettengill, G. A. Neumann, F. G. Lemoine, J. B. Abshire, O. Aharonson, C. D. Brown, S. A. Hauck, A. B. Ivanov, P. J. McGovern, H. J. Zwally and T. C. Duxbury. 1999. The global topography of Mars and implications for surface evolution. Science, 284 (5419), 1495-1503.

Thomas, P., S. Squyres, K. Herkenhoff, A. Howard and B. Murray. 1992. Polar deposits of Mars. In: H. H. Kieffer, B. M. Jakosky, C. W. Snyder and M. S. Matthews (Eds.), Mars, pp. 767-795. University of Arizona Press, Tucson.

Touma, J. and J. Wisdom. 1993. The chaotic obliquity of Mars. Science, 259 (5099), $1294-1297$.

Ward, W. R. 1992. Long-term orbital and spin dynamics of Mars. In: H. H. Kieffer, B. M. Jakosky, C. W. Snyder and M. S. Matthews (Eds.), Mars, pp. 298-320. University of Arizona Press, Tucson.

Zuber, M. T., D. E. Smith, S. C. Solomon, J. B. Abshire, R. S. Afzal, O. Aharonson, K. Fishbaugh, P. G. Ford, H. V. Frey, J. B. Garvin, J. W. Head, A. B. Ivanov, C. L. Johnson, D. O. Muhleman, G. A. Neumann, G. H. Pettengill, R. J. Phillips, X. Sun, H. J. Zwally, W. B. Banerdt and T. C. Duxbury. 1998. Observations of the north polar region of Mars from the Mars Orbiter Laser Altimeter. Science, 282 (5396), 2053-2060. 